\title{
VIENO PORTO VIDEOTORAKOSKOPIJA GYDANT TARPUPLAUČIO, DEŠINIOJO PLAUČIO ŠAUTINI SUŽALOJIMĄ: KLINIKINIS ATVEJIS
}

\author{
Nerijus Šileika, Aleksandras Bagajevas \\ Klaipèdos universitetinè ligoninè, Krūtinès chirurgijos skyrius
}

\section{Ivadas}

Lietuvių autorių straipsniuose mažai informacijos apie šautinius vaikų sužalojimus.

Jungtinėse Amerikos Valstijose (JAV) 4,2 \% vaikų (nuo 0 iki 17 metu amžiaus) panaudojo šaunamaji ginklą per pastaruosius metus (1). Šautiniai vaikų sužalojimai yra trečia pagal dažnị mirties priežastis tarp JAV vaikų (nuo 1 iki 17 metų amžiaus) (2).

JAV kasmet miršta 1300 ir gydoma 5790 vaikų dèl šautinių sužalojimų. Tarp JAV vaikų mažèja mirčių dèl netyčinių susižalojimų ir žmogžudysčių, tačiau dideja mirčių dèl savižudybių šaunamaisiais ginklais (3).

Vaizdo torakoskopinès operacijos (videoassisted thoracoscopic surgery, VATS) yra saugios ir efektyvios gydant vaikų krūtinès ląstos ligas dèl mažesnès traumos ir pooperacinių skausmų, trumpesnès drenų laikymo trukmès ir trumpesnio pooperacinio lovadienio (4).

Šiame straipsnyje pristatysime vaiko šautinio sužalojimo klinikini atveji.

\section{Klinikinis atvejis}

10-ies metų berniukas atsiųstas ị mūsų ligoninę dèl šautinio kaklo sužalojimo. Ligonị sužalojo bendraamžis draugas žaisdamas pneumatiniu ginklu. Atvykęs skundžiasi pasunkejjusiu kvèpavimu, krūtinès ląstos skausmu ryjant seiles.

Atvykus bendra būklè patenkinama, stabili. Sąmoningas. Liežuvis drėgnas. Plaučiuose alsavimas išklausomas abipus. AKS 128/70 mmHg, ŠSD 85 k./min. Pilvas minkštas, peristaltika normali. Kakle virš fossa jugularis $0,5 \mathrm{~cm}$ šautinè žaizda.

Bendras kraujo tyrimas: leu- 14.87; Hb- 125; tromb.- 301.

Krūtinès ląstos KT: tarp raktikaulių stebima nedidelè poodinè emfizema, tarpuplaučio audiniai edemiški, sunkiai diferencijuojasi struktūros, galima įtarti pakraujavimą, dešiniojo plaučio viršutinès skilties S2 segmente stebimas metalinis svetimkūnis, dešinèje pleuros ertmèje $1,8 \mathrm{~cm}$ skysčio ruožas (30 HV) (1,2 pav.).

Ligonis skubiai operuotas. Dešiniajame krūtinès ląstos šone padarytas $3 \mathrm{~cm}$ pjūvis naudojant vieno porto torakos- kopinès chirurgijos techniką, videotorakoskopu apžiūrèta dešinè pleuros ertmė: pašalinta $200 \mathrm{ml}$ kraujo su krešuliais, tarpuplautyje, stemplès projekcijoje stebima hematoma, pašalintas metalinis svetimkūnis iš dešiniojo plaučio viršutinès skilties S2 segmento, plautis susiūtas, padaryta hemostazè. Dešinejje pleuros ertmejje paliktas vienas silikoninis drenas (16 Fr diametro). Žaizda užsiūta.

Ligonis tolimesniam pooperaciniam gydymui perkeltas ị reanimacijos ir intensyvios terapijos skyrių.

Sekančią dieną padaryta kontrolinė krūtinès ląstos KT su peroraliniu kontrastavimu: tarpuplaučio hematoma nedidejja, stemplès vientisumas nepažeistas.

Tolimesniam gydymui perkeltas ị KUL krūtinès chirurgijos skyrių. Kontrolinèse plaučių rentgenogramose kliniškai reikšmingo turinio pleuros ertmėse nèra (3). Ketvirtą pooperacinę parą pašalintas dešinès pleuros drenas. Penktą pooperacinę parą ligonis išleistas ị namus tolimesniam ambulatoriniam gydymui. Pooperaciniu periodu komplikacijų nestebèta.

\section{Diskusija}

Šaunamieji ginklai pradèti naudoti dar Napoleono laikais.

Nelaimèliai turètų būti ịvertinti ir pradèti gydyti laikantis ATLS (Advanced Trauma Life Support) rekomendacijų.

Faktoriai, galintys turèti įtakos letalinei baigčiai: sistolinis arterinis kraujo spaudimas $<90 \mathrm{mmHg}$, pradinè kūno temperatūra $<34 * \mathrm{C}(6)$; bazių deficitas -8 ir daugiau padidina mirties riziką $25 \%$ (7).

Krūtinès ląstos šautiniai sužalojimai lyginant su kitų sričių šautiniais sužalojimais yra pagrindinè mirties priežastis per pirmą valandą po patekimo ị ligoninę, dèl to skubios intervencijos būtinos (8).

Turi būti skubiai ịvertinama ir gydoma dèl penumo-/ hemotorakso drenuojant pleuros ertmę. Chiruginis gydymas indikuotinas, jei per pleuros drenus išsiskiria $>20 \%$ vaiko kraujo tūrio ar besitęsiant kraujavimui 2 ar $>\mathrm{ml} / \mathrm{kg}$ per valandą. Ligoninès, užtikrinančios galimybę padaryti torakotomiją prièmimo skyriuje (širdies tamponados atveju), ženkliai pagerina išgyvenamumą (nuo 5 iki 50 \%) $(9,10,11)$. 


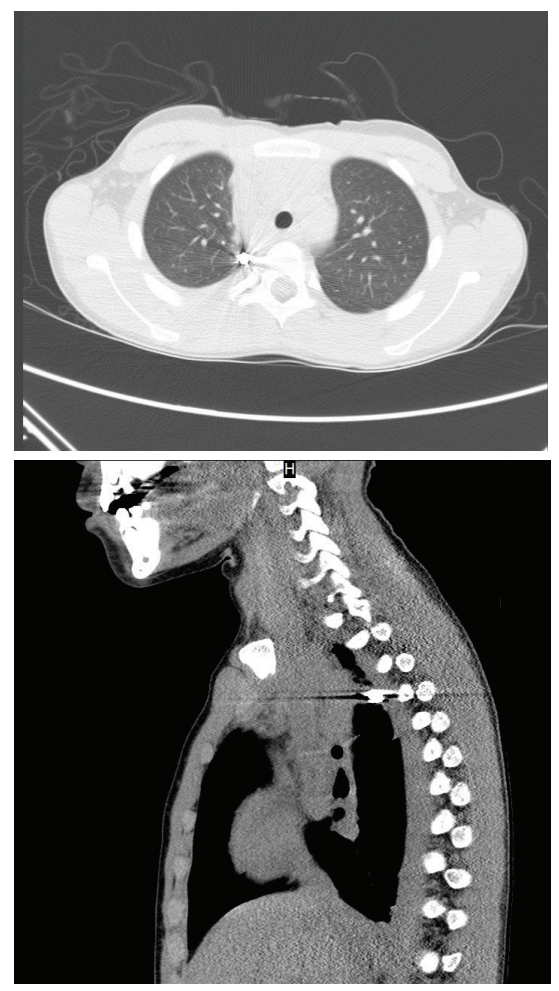

1, 2 pav. Tarpuplaučio hematoma, skystis dešinèje pleuros ertmèje, dešiniojo plaučio viršutinès skilties metalinis svetimkūnis

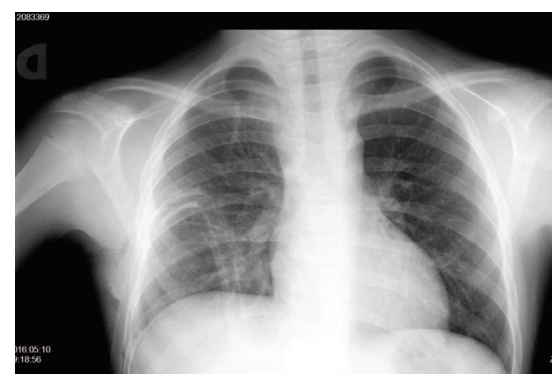

3 pav. Pooperacinėje plaučių rentgenogramoje abu plaučiai oringi, turinio pleuros ertmèse nèra

Vaizdo torakoskopinès operacijos ( $v i$ deoassisted thoracoscopic surgery, VATS) yra saugios ir efektyvios gydant vaikų krūtinès ląstos ligas dèl mažesnès traumos ir pooperacinių skausmų, trumpesnès drenų laikymo trukmès ir trumpesnio pooperacinio lovadienio (4). Mūsų skyriuje naudojama vieno porto torakoskopinès chirurgijos technika.

\section{Išvados}

Patyrę krūtinès ląstos šautinius sužalojimus vaikai turi būti skubiai apžiūrimi ir gydomi.

Vaizdo torakoskopinès operacijos (videoassisted thoracoscopic surgery, VATS) yra saugios ir efektyvios gydant vaikų krūtinès ląstos ligas dèl mažesnès traumos ir pooperacinių skausmų, trumpesnès drenų laikymo trukmès ir trumpesnio pooperacinio lovadienio.

\section{Literatūra}

1. Finkelhor D, Turner HA, Shattuck A, Hamby SL. Prevalence of childhood exposure to violence, crime, and abuse: results from the national survey of children's exposure to violence. JAMA Pediatr 2015;169(8):746-754pmid:26121291.

2. Centers for Disease Control and Prevention, National Center for Injury Prevention and Control. Web-based injury statistics query and reporting system (WISQARS). 2005. Available at: www.cdc.gov/injury/wisqars. Accessed October 2, 2016.

3. Katherine A. Fowler, Linda L. Dahlberg, Tadesse Haileyesus, Carmen Gutierrez, Sarah Bacon. Childhood Firearm Injuries in the United States. Pediatrics 2017.

4. Rescorla FJ, West KW, Gingalewski CA, Engum SA, Scherer LR 3, Grosfeld JL. Efficacy of primary and secondary video-assisted thoracic surgery in children. J Pediatr Surg 2000;35:134-8. https://doi.org/10.1016/S0022-3468(00)80030-5

5. Ghouri M. Air gun injuries: a growing problem in the UK. Br J Hosp Med (Lond). 2008 Jul;69(7):417.

6. Tyburski JG, Wilson RF, Dente C. et al.: Factors affecting mortality rates in patients with abdominal vascular injury. J Trauma 2001; 50:1020-1026. https://doi.org/10.1097/00005373-200106000-00008

7. Kincaid EH, Chang MC, Letton RW. et al.: Admission base deficit in pediatric trauma. The study using NDTB. J Trauma 2002; 51:332-5. https://doi.org/10.1097/00005373-200108000-00018

8. Nance ML, Branas CC, Stafford PW et al.: Nonintracranial fatal firearm injuries in children: implications for treatment. J Trauma 2003; 55:631-5.

https://doi.org/10.1097/01.TA.0000035090.99483.0A

9. Blake DP, Gisbert VL, Ney AL. et al.: Survival after emergency department versus operating room thoracotomy for penetrating cardiac injuries. Am Surg 1992; 58:329-333.

10. Velmahos GC, Degiannis E, Souter I. et al.: Outcome of a strict policy on emergency department thoracotomies. Arch Surg 1995; 130:774-7. https://doi.org/10.1001/archsurg.1995.01430070096019

11. Aihara R, Millham FH, Blansfield J et al.: Emergency thoracotomy for penetrating chest injury: Effect of an institutional protocol. J Trauma 2001; 50:1027-1030.

https://doi.org/10.1097/00005373-200106000-00009

\section{UNIPORTAL VIDEOTHORACOSCOPY (VATS) IN TREATING MEDI- ASTINUM, RIGHT LUNG GUNSHOT INJURY: A CASE REPORT N. Šileika, A. Bagajevas}

Summary

There are too little information about Lithuanian children gunshot injuries among Lithuanian authors.

Recent evidence from the National Survey of Children's Exposure to Violence indicates that $4.2 \%$ of children aged 0 to 17 in the United States have witnessed a shooting in the past year. 
Firearm-related deaths are the third leading cause of death overall among US children aged 1 to 17 years.

Nearly 1300 children die and 5790 are treated for gunshot wounds each year in US. Unintenional firearm deaths and firearm homicides is decreasing, but firearm suicides are showing a significant upward trend.

Video-assisted thoracoscopic surgery (VATS) is safe and effective in treating children thoracic diseases because of redu- ced operative trauma and reduced postoperative pain, and shorter postoperative stay.

We present a clinical case of the 10 year old boy who was injured with air-rifle.

Correspondence to: nerijus01sil@yahoo.com

Gauta 2017-11-06 